\title{
Vivian Pound Was a Man? The Unfolding of a Research Project
}

\author{
Alison Prentice
}

\section{Correcting a mistake}

It was not a major shock to find out that Vivian Pound was really a man, despite the fact that I had thought Pound a woman for the few years that I had been conscious of the existence of this early twentieth-century Canadian physicist. But it was certainly a surprise, and not a little humbling, to learn in the spring of $2000^{1}$ that Pound, a physicist who earned a doctorate from the University of Toronto in 1913, was not a female of the species, as I had thought, but a male. In three essays on early twentieth-century women physicists published between 1996 and 1999, I had erroneously identified Vivian Pound not only as a woman, but as the first woman at the University of Toronto to earn a Ph.D. in physics. $^{2}$

The error first appeared in a list of all the women who earned doctorates in physics at Toronto in the years between 1897 and 1975, a list compiled by a research assistant from two bibliographies enumerating doctorates granted by the university in that period. Pound's was the first of thirteen names. This was a fascinating and important document for a historian trying to find out how many women had managed to complete doctorates in physics at the University of Toronto and to learn something about who they were. Unfortunately, the sources for the list provided names only and no further clues about graduates' gender. ${ }^{3}$

1. E-mail from Charles Levi, 12 June 2000.

2. Alison Prentice, "The Early History of Women in University Physics: A Toronto Case Study,” Physics in Canada/La Physique au Canada 52, 2 (March/April 1996); "Elizabeth Allin: Physicist," in Great Dames, ed. Elspeth Cameron and Janice Dickin (Toronto: University of Toronto Press, 1997); and “Three Women in Physics,” in Challenging Professions: Historical and Contemporary Perspectives on the History of Women's Professional Work, ed. Elizabeth Smyth, Sandra Acker, Paula Bourne, and Alison Prentice (Toronto: University of Toronto Press, 1999).

3. The research assistant, an outstanding researcher who should in no way be blamed for the Vivian Pound error, produced the list for me in the early 1990s. The bibliographies consulted were University of Toronto Doctoral Theses, 1897-1967, A Bibliography, compiled by Judy Mills and Irene Dombra (Toronto: University of Toronto Press, 1968),

(c) Historical Studies in Education/Revue d'histoire de l'éducation 13, 2 ( 2001): 99-112 
I should admit that there was always a slight question mark in my mind about Vivian Pound. My research assistant did do some further inves-tigation which uncovered the following information. First we learned that, after the doctorate was awarded, Pound had taught briefly at Queen's. This seemed unusual for a woman scientist, but not impossible; most of the women physicists who earned doctorates from Toronto in the 1920s and 1930s had also done some university teaching and at least three women from that period (two with doctorates, one with a master's degree) had eventually had lifetime careers as members of that university's physics faculty. It was a little more surprising, perhaps, to learn that Pound had also been in business for a few years and had finally made a career teaching at an American university. ${ }^{4}$ But once again, I rationalized that these career moves were not totally out of line for an early twentieth-century woman physicist. Business undertakings were not uncommon for Canadian women in most periods of our history; and Canadian academic women often did end up working at American colleges and universities in the early twentieth century, since so few university jobs were available to them in Canada. ${ }^{5}$

Still, there were niggling doubts. I must have noticed that Elizabeth Allin's history of the physics department at Toronto did not call attention to Pound in her discussion of the women who obtained doctorates or worked in physics at Toronto during the years between 1907 and $1932 .{ }^{6}$ But there were plausible reasons for this. Pound was before Allin's own time at the university and her

and University of Toronto Doctoral Theses, 1968-1975: A Bibliography (Toronto: University of Toronto Press, 1977). The other names and the dates of their doctorates: Mattie Levi, 1926; Elizabeth Cohen, 1929; Elizabeth Josephine Allin, 1931; Florence Mary Quinlan, 1932; May Annetts, 1933; Olga Mary Mracek Mitchell, 1962; Helen Sarah Freedhoff, 1965; Patricia Ann Speight, 1969; Lynn McNeille Hastie, 1971; Maria Wiszniewska, 1973; Phyllis Betty Dworkin-Charlesworth, 1974; Dalia Marta Spektor, 1974. Beatrice Reid Deacon, 1929, who, according to Charles Levi, appears in Mills and Dombra as having a Ph.D. in chemistry, was not on the list but should have been. 4. American Men of Science, $10^{\text {th }}$ ed. (New York: Bowker, 1961) was the source of this information. Note that American Men, despite its title, included women scientists along with the men.

5. See Alison Prentice, "Laying Siege to the Professoriate," in Creating Historical Memory: English-Canadian Women and the Work of History, ed. Beverly Boutilier and Alison Prentice (Vancouver: UBC Press, 1997), 197-232 for examples of women historians who followed this route.

6. Elizabeth J. Allin, Physics at the University of Toronto, 1843-1980 (Department of Physics, University of Toronto, 1981). See esp. 11-12. Women are also listed on pages 15 and 16. 
discussion of the women was also very brief. Allin belonged to an era when it often seemed best to use initials for both men and women; she clearly did not want to make too much of what women did or did not do. Nevertheless, I admit that somewhere in the back of my mind, there were concerns - however vague-about Vivian Pound's history and identity. I wanted to know more about this early physicist, but did not initiate any further investigation. ${ }^{7} \mathrm{My}$ main interest was the women who remained at the University of Toronto. And, especially after the fall of 1995, there were always other priorities, both personal and intellectual. Organizing my retirement, a relocation from Ontario to British Columbia, teaching on the internet: none are sufficient excuse, but they do explain perhaps why no more work was done on Vivian Pound.

Fortunately, the granddaughter of Mattie Levi Rotenberg, the physicist who actually was the first woman to receive a doctorate in physics from the University of Toronto, reopened the question. Nessa Rapoport was writing an essay on her grandmother and wanted to validate the family claim that Rotenberg had, in fact, been the first woman physicist to earn a Toronto Ph.D.. Was the family right or wrong? Did Vivian Pound deserve the honour or did Mattie Rotenberg?

Nessa Rapoport contacted her cousin Charles Levi. The latter was ideally situated to check whatever records there might be to answer her question, since he was in the archives daily as a researcher for the University of Toronto history project and knew the sources inside out. Charles himself had wondered about the whole question when he read the essays dealing with women in physics at Toronto that I had donated to the project archive. Nor was he the only sceptic, as I later learned. Marianne Gosztonyi Ainley was also sure that Mattie Levi Rotenberg had been the first woman to earn a doctorate in physics at Toronto, but had not pressed the point with me (although she had with my husband) when the issue came up at a conference we both attended in 1998.

7. One thing that did not create a problem for me was the spelling "Vivian," as opposed to "Vivien." I have since learned that British usage, which has undoubtedly been influential in Canada, often assigns the first spelling to men, the second to women; however, some reference sources, both British and American, cite "Vivian" as a male or female name. My thanks to Rebecca Coulter and Wyn Millar, who raised and looked into this question for me. 
If I heard her objections to the Vivian Pound theory in 1998, I apparently blocked them completely from my conscious mind. ${ }^{8}$

How did Charles Levi unravel the mystery? The bibliographies from which Pound's name had originally been culled did not identify students by gender, nor did the university's early calendars listing students and faculty. ${ }^{9}$ It was only with the publication of the university directories beginning in 1921 that women students, staff, and faculty were distinguished by "Mrs." or "Miss," and Pound's doctorate was granted in 1917. ${ }^{10}$ Levi knew, however, that there was one source that would give him the answer, if Pound had been an undergraduate as well as a graduate student at Toronto. This was the university's yearbook, Torontonensis. And, indeed, Vivian Pound's name, along with his obviously male portrait, do appear on page 82 of Torontonensis for the year 1907. We learn from the yearbook note that Vivan Pound was a graduate of Niagara Falls Collegiate Institute, and that at Toronto "the study of Mathematics and Physics" had been his "hobby." A “diligent student," he was taking the physics option in his fourth year. The yearbook predicted that "the name of Pound may yet be famous in the scientific world.” Whether famous or infamous, then or now, Vivian Pound was certainly a man. Thanks to Charles Levi and Torontonensis, Nessa Rapoport had the confirmation she needed for her essay on her grandmother. ${ }^{11}$ However, her good news was not such good news for me. How could I correct my thricerepeated mistake?

\section{Motives for research and getting started}

There are often multiple factors that come together and motivate our scholarly work and my recent explorations in the history of University of Toronto women in physics were no exception. My dilemma about Vivian Pound turned out to be a crucial catalyst for new research and writing. As a historian, I am only too aware of how mistakes get into the literature and can be endlessly repeated

8. The conference was the Biennial Conference of the Canadian History of Education Association/L'Association canadienne d'histoire de l'education, Vancouver 1998. [Telephone conversation with Marianne Ainley, September 2000.]

9. University of Toronto Calendars, University of Toronto Archives (UTA), P78-0021.

10. University of Toronto Directories of Staff and Students, UTA, P78-0171.

11. See Nessa Rapoport, "Recollections of Mattie Levi Rotenberg," Re://Collections 2, 1 (Spring 2000) (Published by the Jewish Women’s Archive, Brookline, Mass.). 
down the years. It thus seemed vital to me that my error be corrected as soon as possible, and in some public way. But there were other factors at work as well. I initially became interested in women physicists in the context of a general project on women who made it into the professorial ranks in Canada's universities in the early twentieth century. As a follow-up to my earlier studies of Toronto women physicists in the first half of that century, I'd always thought that I ought to write some day about the generations of women who had completed their doctorates and become physicists in the second half of the century. Now the time seemed ripe. For one thing, I had the list referred to above which, in addition to the physicists listed for the period before1940, included seven women whose Toronto doctorates dated from the 1960s and early 1970s. And sometime before 1995 when thinking about this further study, I had also asked a friendly administrator in the physics department for the names and addresses of the women who earned doctorates in the period between 1975 and $1990 .^{12}$

A list was kindly provided, but I never got around to contacting the women. Why? Partly lack of time; partly because my interest in women physicists was far from detached. Indeed, it was my marriage to a member of the Toronto department of physics that had undoubtedly prompted in the first place my desire to delve so deeply into the subject. During the 1980s and early 1990s, the fact that the Toronto physics department had been unable to hire any women as tenure-stream members of faculty, or to retain them when one or two were finally hired, had become a significant concern in our household. Once I discovered, in other earlier research, that Toronto had both produced and employed quite a few women physicists during the first half of the twentieth century, ${ }^{13} \mathrm{I}$ became doubly motivated: first to make that almost unknown fact better known, which I tried to do by writing the three essays on women in physics cited above; and secondly, to try to understand what had happened in the second half of the century, when women seemed, relative to men, to have lost so much ground in university physics. It was the second of these two projects that never got off the ground, in part perhaps because I felt too close to the

12. This list was provided by Marianne Khurana in the early 1990s, and included the most recent address that the department had for each of the women at the time. I am grateful to Marianne for her assistance; without her list I could not have proceeded. 13. See Alison Prentice, "Bluestockings, Feminists, or Women Workers? A Preliminary Look at Women's Employment at the University of Toronto,” Journal of the Canadian Historical Association (1991): 231-61. 
contemporary problem while still living in Toronto. Later, when I moved to BC and retired from teaching, other work and interests took priority. It was my felt need to correct the error regarding Vivian Pound that finally provided the necessary impetus for another project on women physicists.

But there were other factors also at work. A major one was the fact that one of my three earlier essays - the one outlining the story of the University of Toronto women physicists who earned their doctorates before 1940-had been published in a special issue of Physics in Canada that few readers outside of physics were ever likely to see. ${ }^{14}$ It seemed useful to rework that material for a wider audience. Secondly, I had been asked to contribute an essay on women in physics to a projected volume, to be co-edited by Ruby Heap and Monique Frize, on the history of Canadian women in science and engineering. ${ }^{15}$ This proposal, which landed on my desk in the spring of 2000 shortly before the arrival of the news about Vivian Pound, could hardly have come at a better time. To be able to offer an essay to such a collection certainly made the prospect of launching on another study of women physicists more inviting.

The first step was to compose a letter to the twenty-two women physicists whose names were to be found on my two lists, a task that I completed in July, 2000. The letter was quite long. It provided a brief overview of who I was and what I had so far written on the history of Toronto women physicists. It also said something about my wish to correct the Vivian Pound error, as well as to write about women physicists whose careers unfolded during the second half of the twentieth century. I designed a package that would include, along with my letter, a list of the twenty-two women who were receiving it, with a request that I be alerted to the existence of anyone known to be missing from the list. The package also included a one-page questionnaire and a permission form. In early August, I had the opportunity to spend a few days in Toronto and, during that visit, enlisted the help of the university's Office of Advancement to check the addresses that I had, which by that time were more than five years out of date, and to ask for those that I did not have. ${ }^{16}$

14. “The Early History of Women in University Physics,” note 2.

15. See Alison Prentice, "A Blackboard in Her Kitchen: University of Toronto Women and Physics, 1890-1990,” forthcoming in Canadian Women in Science and Engineering: Historical and Contemporary Perspectives , ed. Ruby Heap and Monique Frize (Ottawa: University of Ottawa Press).

16. Many thanks to Allison Lee, of the Office of Advancement, who updated my list. 
During the same visit, the packages were pulled together; ${ }^{17}$ eventually they were mailed. By September, I already had several fascinating replies to my questionnaire. Not long after their arrival, I received the program for the fall 2000 conference of the Canadian History of Education Association/L'Association canadienne d'histoire de l'education, and noticed there was a space into which a paper on my research might fit. The President of CHEA and chair of the conference, Rebecca Coulter, kindly welcomed the idea of a paper on women physicists to fill that slot, and "Vivian Pound Was a Man? The Joys and Sorrows of Studying Gender in University Physics" was added to a session on the history of women and the professions. This provided the final spark that committed me to the project.

\section{Methods: new problems for an old researcher}

Now began the difficult part. By the first week in October eight women had contacted me and agreed to participate in my study ${ }^{18}$ and, by the time I began writing the paper, I had managed to talk and/or correspond with six of them. Thus the oral history section of the paper I presented at the CHEA/ACHE conference was based on my contacts with six women, two with doctorates from each of the three decades under scrutiny: the 1960s, the 1970s and the 1980s. When I returned from the conference at the end of October, an e-mail responding to the questionnaire awaited me from another woman whose Ph.D. dated from the 1980s. I also arranged for and conducted the interviews with the two remaining contacts I had, both of whom were her contemporaries.

This mode of proceeding was not without problems. The first difficulties may have had to do with the somewhat general nature of my one-page questionnaire, and the very different ways people responded to it. In the questionnaire I asked respondents about their decision to become physicists, about the influence of their early schooling, and if there had been any barriers on their path. I also asked them to record their degrees and current positions. A

17. I am grateful to OISE/UT, where I continue to have some access to shared office space, and to Elizabeth Smyth whose assistance was essential to the completion of this task.

18. One of these women had not been on my original list of twenty-two; indeed, I eventually learned that there were at least four women who should have been on the list who were missing from it. 
third question tackled their decision to study at Toronto, and asked for comparisons to other universities, if relevant; a fourth queried their choice of sub-field in physics for graduate study. Question five attempted to explore their experiences as students at the University of Toronto and asked if they thought their experience had been different from that of male students. I then went on to ask about respondents' employment history, their views on the present climate for women in physics, at Toronto or elsewhere, and change over time-if they thought there was any-in this regard. A final, open-ended question invited participants to write about any other topics they wished to pursue. The written responses I received not only varied greatly in what their writers chose to emphasize, but in the amount of detail they provided.

Because I was aware of the time constraints under which my respondents laboured and therefore wanted to be flexible, I had also made it clear that I was happy to conduct telephone interviews with those who didn't have time to write their answers. Five of the women chose this option; in one additional case, a respondent who answered the questionnaire also made time for a telephone conversation. Later on, during a visit to Toronto after the CHEA conference, I was able to meet and talk personally to two of the women who had provided written responses to my questionnaire, as well as to two of those with whom I had conducted telephone interviews.

The telephone interviews generally followed the format of the questionnaire, but since I had known four of my respondents from their graduate student days at Toronto, it became increasingly easy to shift gears when other subjects came up. I found that topics broached in one interview tended to lead to new questions and topics in subsequent ones. In each case, I made notes, wrote them up as soon as I could after our conversation, and then mailed my transcripts to the interviewees for their correction and approval. I did the same with new information gained when I met three of the earlier respondents in Toronto. Eventually, I also mailed each of the people involved in the project a copy of my CHEA paper, so that they could have an idea of how I was using the information they had given me. Because this first paper had been written while the research was ongoing, subsequent versions of the paper were quite different from it, which may have seemed problematic to some respondents in that the first version was much longer and also more optimistic in tone than the versions that followed.

A second, trickier series of problems arose out my historian's desire to use the real names of the participants in my study, if they 
agreed. Most of my respondents waited to see what their transcripts and my writing looked like, before sending in their permission forms. The form itself also complicated the process, because it was fairly intricate. It included a request for permission to use respondents' names, as well as permission to use their words in my essay for the Heap/Frize volume. In addition, I asked for separate permissions to have their transcripts deposited in an appropriate archive for use by other scholars, and for their use in radio broadcasts or other media, or in later writings by me. I also included a section in which respondents could add any particular restrictions they wished to place on their transcripts, my use of them, or the use of these transcripts by other researchers. All this may seem unnecessarily complex,but I join other feminist scholars in feeling that it was vital to provide as many choices as I could to people who were so generously giving their time and their personal stories to my research and writing. The form also pointed out each participant's right to withdraw from my study at any time, should she choose to do so. Gratifyingly, no-one chose that option. ${ }^{19}$

The result of this approach was a process of ongoing negotiation, first about what could (or should) appear in the essay, and, second, about what would be in the final versions of the transcripts, and whether these could be used in the future and/or deposited in an archive. In the end, two of the nine respondents were happy to have their stories told in the essay for the book edited by Heap and Frize, or in future writings by me,but preferred that their transcripts not be exposed to other eyes than mine. The other seven had no problem with the idea of having their materials deposited in an archive and possibly used by other scholars. Several of these, however, have asked that particular stories they told me be deleted either from the Heap/Frize essay or from their transcript, or both. Two also expressed concern about the use of their names. One person who initially felt that her name ought not to be used decided that it could be after reading the CHEA version of the paper,but another eventually concluded that she preferred to be anonymous. In the case of a third respondent, I felt that it was

19. Because I was no longer employed by an academic institution and my research had no external funding, my project and permission form were not subjected to an ethical review. However, I did try to follow the spirit of the OISE/UT ethical review documents with which I was familiar. In addition, I learned a great deal about permission forms (as well as other issues in oral history) from a workshop conducted by Theresa Healy for the Victoria Branch of the Women's History Network of British Columbia in the spring of 1998. 
safer to tell her somewhat difficult story without revealing her name. She later wrote confirming her preference for anonymity. All three of these participants earned their doctorates in the 1980s and I am left with concerns about my use of the younger women's names that are still not fully resolved in my own mind. Should I have used pseudonyms for all of the women, as most sociologists do? Or at least for those whose doctorates date from the 1980s, since they are still in mid-career and perhaps vulnerable to misunderstanding arising from my use of their stories?

If I had chosen to use pseudonyms, or had not engaged in negotiations with my respondents, would the result have been different "truths" than the ones that my writing about these women currently reflects? The answer is yes. One very damaging remark that a professor made to one of the participants is now deleted from the record; in general, the emphasis is on the positive rather than the negative. Although ambivalent about this, in the end, I do understand the wish of most of my respondents that the emphasis be on what worked for them rather than on what did not. It's important to note, in this context, that nearly all of the participants were generally happy with the ways in which their lives and careers had unfolded, although there may have been initial difficulties. With one exception, if there were women whose experiences were very negative or did not improve with time, they did not respond to my inquiry. Nor did my study explore the histories of women who, for whatever reason, did not pursue doctorates at Toronto, or who initiated Ph.D.s but dropped out somewhere along the way. Capturing the histories of women "would-be" physicists who did not succeed might have resulted in a very different story.

Since the transcripts and permission forms were going back and forth along with various versions of the essay that included most people's names, participants got to read about each other before they had all decided what they wanted to do about their names. This may have been problematic for the few who were uncertain-especially the two respondents who eventually decided that they preferred anonymity. Yet the feedback I received suggests that nearly all of the participants were really interested in learning about each other, as well as in learning what the essay had to tell them about their early twentieth-century Canadian female predecessors. Indeed, the participants' apparent enjoyment of the project was one of the major rewards of the collaborative process I tried to foster. Several women were happy to learn where others were currently located; thus an additional reward was my feeling that a greater sense of their community might have been fostered 
among the women who collaborated in my work. In the end, my historians' wish for the "truth" of people named with their own names was largely satisfied. To my way of thinking, using their names is a way of honouring their work. An important further result of naming the women is the possibility that a future researcher could expand on, or do revisionist work related to, my study of these women physicists, knowing (with the exceptions noted above) exactly who my respondents were.

The literature on the ethics of doing oral history is increasingly vast and feminists have been particularly concerned in taking up this subject. But recent studies do seem to indicate that each project produces its own problems and that, overall, there are still many unresolved issues involved in doing this kind of research. ${ }^{20}$

\section{Back to the documentary record}

British Columbia's Jean Barman has written entertainingly about the "mad dash method" of doing archival research. "By this I mean getting up at 4 or 5 A.M to catch the 7 A.M. ferry to get to the archives by its opening at 9:30 and then another dash back at about 7:30 in the evening for the final, 9 P.M. ferry and so home by midnight, if all goes well.” Jean lives in Vancouver and the BC Archives that she refers to are on the island in Victoria. As she comments, "These mad dashes concentrate the mind wonderfully." ${ }^{21}$ Jean should try dashing from Victoria to Toronto. And, I have to add, the mad dash method not only concentrates the mind, it can also muddle it. Had I not been commuting between Victoria and Toronto between 1995 and 1998, might the Vivian Pound error have been checked at some point before its repetition in a total of three published papers?

The calamity of Vivian Pound certainly led me to take a few days after the CHEA conference, in October, 2000, to look once again at the records on the early twentieth century women physicists associated with the University of Toronto. I had

20. See the interesting discussions, the various problems raised, and the useful references to be found in the articles gathered in Linda Cullum and Diane Tye, eds., "Feminist Qualitative research/Feminisme et recherche qualitative," $R F R / D R F$ 28, 1-2 (Spring/Summer 2000). My thanks to Marge Reitsma-Street for alerting me to these discussions, which also encouraged me to persist with the writing of this article.

21. Barman, "Sex and Violence in the BC Archives: Adventures in Historical Detection,” British Columbia Historical News 34, 1 (Winter 2000/2001): 6. 
previously focused chiefly on the period prior to 1940 when these women were students and achieved their doctorates. The time to explore the university directories (and other records) fully for the period after 1940 had never been available to me. ${ }^{22}$ Yet several of the women whose careers interested me had continued to be employed by the physics department at Toronto after 1940; in one case, into the early 1970s. Going back to the university archives to learn more about these women physicists led to some interesting findings. For one thing, I learned that more than one woman without a Ph.D. in physics had long-term jobs with the Toronto physics department in the mid-century decades. Especially during the second world war, several women without doctorates taught for the department and some continued to do so after the war. I also learned that women, with and without Ph.D.s, taught for far longer than I had imagined possible, given the fact that in most cases their appointments were sessional.

It was a special pleasure to track the teaching career of a woman totally unknown to me before I gave the paper at the CHEA meeting in October, 2000. In my audience at that conference sat a relative of Clara Clinkscale Morrison, a woman physicist who taught at Toronto in the 1940s and 1950s. Susan Majhanovich alerted me to Morrison's career and I later heard more about it from Clara Morrison's daughter, Jean Clement. It was a delight to find this career documented in the archives and to be able to tell her story in some detail in the final version of my paper. Re-examining the women physicists' student cards with new questions in mind was also important. ${ }^{23}$ I discovered that one of the early twentiethcentury women physicists that I was interested in, Elizabeth Cohen, had taught in several Toronto secondary schools as well as for the university. In addition, addresses on these cards provided clues to the movements of the women who left Toronto after the completion of their graduate degrees.

Looking back over my own research records also proved interesting, although less productive. What was there that I had not noticed before? Certainly one little item I thought might provide new information on one of the early twentieth-century women

22. I did engage a research assistant, at some point, to explore the directories for the years 1945, 1950, 1955, and 1960, with the intention of creating a database for a quantitative project on all women employed at the university during those two decades. The research was completed but, for a variety of reasons, I was not able to have the data computerized and it remains unused.

23. UTA, A73-0026. 
physicists who left Toronto soon after the granting of their Ph.D.s. The list of University of Toronto women with doctorates in physics that had been compiled for me contained a note about May Annetts Smith that I had never followed up. It suggested that her husband, Charles Smith, ended up in the physics department of the University of North Carolina, Chapel Hill. I checked with the archivist of that university but found that, even if UNC's Charles Smith had once been married to May Annetts, the university's records contained no trace of her. Their Charles Smith had a wife by another name. The ultimate fate of one of Toronto's most brilliant early twentieth-century women physics graduates thus continues to elude me.

Documentary searches, as all historians know, can be neverending. When do we stop researching and start writing? What I have tried to suggest here is that research and writing do not occur in a vacuum. The information we want may or may not be in the archives. Secondly, we may or may not actually manage to find it, given the constraints of our lives. Just as the oral historian's work is a collaboration with her subjects and greatly depends on their interest and willingness to reveal their histories, so the archival historian is negotiating a path constrained by what earlier subjects wished or did not wish to have known, or may not have been able to reveal, given the constraints of their lives and the eras in which they lived. In both cases, we are at the mercy of time. There always seems to be more that we might find out, if only the hours and days stretched out endlessly before us. But they do not. The smooth and linear paths that we might imagine historians taking often turn out to be bumpy and winding.

\section{Conclusion?}

The timing, the nature of the questions, the situation of the historian and her subjects are all contexts that influence the story that gets told and what finally gets into print. And, I hasten to add, the historian also contends with the fact of publishers' and editors' concerns with timing and the resulting deadlines. There are also publishers' and editors' restrictions on length. Partly because I wanted my essay for the book to be edited by Ruby Heap and Monique Frize to reflect my most recent understanding of the early twentieth-century women physicists as well as what I had learned about University of Toronto women physicists who earned their degrees in the second half of the century, the paper grew too long 
and had to be cut. It is now missing many of the stories given to me by the women I contacted for that study.

But it would seem that the historian's process is never-ending. One thing leads to another and the need to remove material from the Heap/Frize essay in order to reduce it to an appropriate length led me to write the article you are now reading. And, if all goes according to plan, the remainder of the material cut from the original essay I wrote for the book edited by Heap and Frize will be the basis for another study, focusing on how physicists in the second half of the twentieth century were educated and learned to be professional scientists. Will that be the end of my journey with the history of women in physics? Clearly, given what I now know about my "winding tracks"24 as a historian, predictions on that score would be unwise.

Nor are my own winding tracks the only ones involved. As this report suggests, historical research seems to be collaborative, even when one is supposedly the sole author of it. Participants include not only the people whose stories got into the written record, and the archivists and research assistants who help to make them known, but also, as the present case illustrates, people who have things to say about their ancestors or relatives. As well, participants include the subjects of oral histories, who have fascinating stories - and their own ideas about how those stories should be told. Nor should I forget to mention the friends who kindly undertake to read one's work and then ask the interesting questions that trigger further thoughts and queries. ${ }^{25}$ What I have discovered-or rediscovered-in this project is that the historian's "truth" is many-sided, fluid and, like the mistaken identity of Vivian Pound, always subject to change.

24. The phrase belongs to Inga Elgqvist-Saltzman, who teaches us to treat women's winding tracks as valuable and creative, if unpredictable. See Elgqvist-Saltzman, "Straight Roads and Winding Tracks: Swedish educational policy from a gender perspective," in Gender and Education 4, 1-2 (1992).

25. I would like to thank Marianne Ainley, Jean Barman, Bill Bruneau, Ruby Heap, Alyson King, Charles Levi, and Marge Reitsma-Street for their insightful and helpful comments on this essay. 